Currently 94\% of all children are transported in child restraint systems. Road accidents statistics show that the number of children killed in passenger cars dropped by $55 \%$ in relation to decrease of $35 \%$ in number of all people killed in road accidents in Poland from 2004 (before the campaign) till 2013.

\section{LESSONS LEARNED FROM CONDUCTING ROAD SAFETY CURRICULUM IN THAI SCHOOLS}

${ }^{1}$ Danulada Jamjuree, ${ }^{2}$ Saifon Srathongphun. 'Srinakharinwirot University, Thailand; ${ }^{2}$ Lampang Hospital, Thailand

10.1136/injuryprev-2016-042156.705

Teaching and learning road safety has been recommended as a core strategy in both nation and international levels. In Thailand, the Ministry of Education has launched a policy to integrate road safety with school's core curriculum since 2003. In 2006, Road Safety Safety Group Thailand(RSC) reemerged road safety curriculum to foster road safety behaviours in children. Beginning with 2 schools in Lampang Province, Northern of Thailand and the number increased later. Now 6 primary and secondary schools in Lampang manage road safety curriculum. This research focused on road safety curriculum, instructional approach, and outcomes found in 6 schools in Lampang Province.

Methods The After Action Review(AAR) was conducted to explore lessons learned in road safety curriculum. Two studies from this curriculum are a content analysis of road safety curriculum in 6 schools and focus group discussion with stakeholders. It was conducted between December 2012 to April 2013.

Results 1. Patterns of integrated road safety curriculum. Results can be described in 4 patterns: (1) themes of road safety that share contents within each subject of school's core curriculum, (2) activities on road safety in one subject that connect to another subjects, (3) integration road safety curriculum within each subject of school's core curriculum, and (4) mix methods of pattern 1 and 2. 2. Key success factors. (1) teacher's knowledge and skills for integrating road safety curriculum to school's core curriculum, (2) school's readiness, (3) teacher's participation and empowerment, and (4) principal's supportive and facilitation. 3. Outcomes. Results found that most of students (1) had increased road safety skills especially in walking on the street, crossing road and using helmet, (2) had more knowledge and understanding about traffic policy, (3) the concern about wearing helmet behaviour increased from $49 \%$ to $88.7 \%$.

Conclusions This study shows that road safety curriculum can be done and works well with school's core curriculum. The success of the application is depended on (1) school's readiness, (2) knowledge and understanding of teachers to road safety curriculum and nature of road safety, (3) administrator's policy and support, and (5) reconcile teacher's attitude at the beginning of taking this curriculum to school.

\section{CHILDHOOD SAFETY EDUCATION IN RURAL UGANDA}

${ }^{1}$ Mary Goretti Nakabugo, ${ }^{2}$ Marissa Swanson, ${ }^{3}$ Olivia Schneider, ${ }^{2}$ David C Schwebel. ${ }^{1}$ Twaweza/Uwezo East Africa; ${ }^{2}$ University of Alabama at Birmingham; ${ }^{3}$ Arlington Academy of Hope

10.1136/injuryprev-2016-042156.706

Background Rural Uganda is an especially hazardous environment for children with limited parental supervision, open fires, speeding traffic, sharp farm tools, and flowing rivers. Effective safety education has the potential to reduce injury risk among this vulnerable population. Although safety instruction is a required component of the national curriculum, schools face challenges of overcrowding, understaffing, lack of resources and teacher training, and absenteeism which may inhibit student learning of safety behaviours. Given this context, there is need to investigate the content, quality and effectiveness of the safety units as currently taught in Ugandan schools.

Objective Qualitatively assess primary teacher perceptions of 1) childhood injury risks in a rural Ugandan community, and 2) the current state of safety instruction.

Results 21 teachers in grades 1-6 from 5 schools in rural eastern Uganda completed surveys on child injuries and safety instruction. Falls, cuts, and burns are considered the most common injuries among children. Children are frequently left without adult supervision, beginning between ages 3-7. Children are especially likely to be alone when either the child or parent is busy farming, fetching water, or at market. Safety units are most commonly taught in grades 1, 2, 4 and 6. The most common topics are safety around roads/transport and safety at home. The most common instructional strategies include providing information/safety rules, safety demonstrations, and first aid training. All teachers report their students adopt safer behaviours after instruction. Only one teacher reports ever receiving training in safety instruction.

Conclusions Injury risk is high in rural Uganda but children often receive inadequate supervision. Teachers are motivated to teach safety skills but lack supportive training and resources. Explicit training and materials developed for Ugandan teachers has the potential to reduce childhood injury risk in rural Uganda.

\section{REDUCING SCHOOL BULLYING WITH THEATRE AND ART}

${ }^{1}$ Corinne Peek-Asa, ${ }^{1}$ Marizen Ramirez, ${ }^{2}$ Jennifer Fawcett. ${ }^{1}$ University of lowa Injury Prevention Research Centre, USA; ${ }^{2}$ Working Group Theatre, New York, USA

\subsection{6/injuryprev-2016-042156.707}

Background Bullying is the most common form of school violence worldwide. School-based bullying prevention programs have shown varying success, and new, innovative programs with a stronger evidence base are needed. Arts-based programming, which appeals to the active emotional brains of adolescents, is a promising approach.

Description of the program Injury prevention researchers and a theatre group collaborated to develop a play called "Out of Bounds," informed by qualitative and policy research. The play tells the story of a cyberbullying event and promotes themes of forgiveness, friendship, identity and labels. "Out of Bounds" was performed in ten Iowa middle and high schools and has more recently been on a national tour. Because viewing a play is unlikely to support behaviour change on its own, the team developed a program of arts-based activities to accompany the play. The activity toolkit is called "HEAR: Helping Educators use Art to Reduce Bullying." Activities were developed for multiple age groups and multiple settings, including classrooms and after school programs. Activities include games, acting, photovoice, reflective writing, drawing, and appreciative inquiry.

Results The play and toolbox were pilot tested through a service learning course with public health students and a school district. The play was performed in eight schools, and teachers chose activities from the toolkit to implement in their classrooms. 